\title{
Food crop production in Nigeria. I. Present effects of climate variability
}

\author{
James O. Adejuwon* \\ Department of Geography, Obafemi Awolowo University, Ile-Ife, Osun State, Nigeria
}

\begin{abstract}
Climate and crop productivity are both characterised by inter-annual variability. The common understanding is that the co-variation is indicative of a simple cause and effect relationship. However, the relationship analysed in this paper is that of crops with complex phases of growth and development responding to a climate that is multivariate, dynamic and heterogeneous. Bivariate correlation, multiple correlation and regression analyses were employed to demonstrate the relationship between crop yield and climate. The crops studied were cowpeas, groundnut, millet, maize, sorghum and rice during the period 1983 to 1999 in the Nigerian Arid Zone. The predictive models generated for cowpeas, groundnut, millet and sorghum were statistically significant with $\alpha \leq 0.05$. Among the more powerful determinants of crop yield were rainfall at the onset and at the cessation months of the growing season. Inter-annual changes in the yield of maize and rice were less sensitive to rainfall variability. In general, the linear models failed to incorporate the separation of crop yield variability from rainfall at higher levels of precipitation. During the long periods with normal and above normal rainfall, crop yield sensitivity tends to be weak. However, during the years with unusually low precipitation, crop yield sensitivity becomes more pronounced. For purposes of developing the appropriate adaptation strategies, it is suggested that a distinction be made between drought with its associated disasters and the less hazardous but more frequent inter-annual climate or rainfall variability.
\end{abstract}

KEY WORDS: Impact · Climate variability $\cdot$ Crop yield $\cdot$ Arid zone

\section{INTRODUCTION}

This study analyses the impact of climate variability on the yield of the major crops cultivated in the Nigerian Arid Zone, using Bornu and Yobe states (see Fig. 1) as a case study. The study was intended to: (1) Identify and assess the significance of the climatic variables responsible for inter-annual changes in crop yield; (2) Determine the proportion of inter-annual crop yield variability that could be ascribed to climate variability; (3) Generate and test predictive models that could be used to estimate crop yield from climate data; (4) Assess the impact of the climatic conditions of each growing season on crop yield over the period of assessment; (5) Characterize the weather pattern that resulted in the most significant negative impacts on crop yield.
Yield is mainly determined by ecological factors including climate, soil and pests and diseases. Changes in farm operational schedules could also lead to changes in productivity and therefore contribute to inter-annual changes in crop yield. Thus, farm operations including land preparation, choice of cultivars, planting density, application of irrigation water, pesticides, herbicides and fertilizers could result in changes in crop yield if they vary on a yearly basis. However, conventional wisdom usually ascribes inter-annual changes in crop yield mainly to the climate, because it has the same annual time resolution as crop productivity.

Crop growth and development are affected by solar radiation, relative humidity, rainfall, temperature, and cloud cover which combine to produce the observed impacts of climate on crop yield (Daubenmire 1973). 
Each of these factors is also composed of elements, which separately affect the different functions of the crop plants in the course of their growth and development. For example, the phenological and physiological effects of minimum and maximum temperature on crop plants may differ significantly. The same crop plants invariably require specific minimum and maximum temperatures for optimum performance at various stages of their life cycles.

In the tropics, 'the growing season lasts, thermally, the whole year (Riehl 1954, p. 34)'. There is never the danger of ground frosts damaging crop plants and leading to crop failure. For example, the coefficient of variation $\left(\mathrm{CV}_{i} \mathrm{SD} / \mathrm{mean}\right)$ of maximum temperature averages $<5 \%$ across climate zones in Nigeria. On the other hand, the CV of monthly rainfall can be as high as $600 \%$ in certain locations and during certain months of the year. There is no month with inter-annual CV < $20 \%$. In other words, the effective determinants of inter-annual changes in crop yield should be sought in the variability of the rainfall element of climate.

\section{STUDY AREA}

The study area is coterminous with the present Bornu and Yobe states in Nigeria (Fig. 1). It covers an area of about $116000 \mathrm{~km}^{2}$ lying between 10 and $13^{\circ} \mathrm{N}$ and between 12 and $15^{\circ} \mathrm{E}$ in NE Nigeria, to the west of Lake Chad. It is part of the Arid Zone of Nigeria, which consists of the Sudan Savannah and Sahel Savannah ecological zones. The Sahel area lies to the north and occupies about $40 \%$ of the study area, while the Sudanic area occupies the southern $60 \%$. The rainfall is highly seasonal with marked wet and dry seasons.

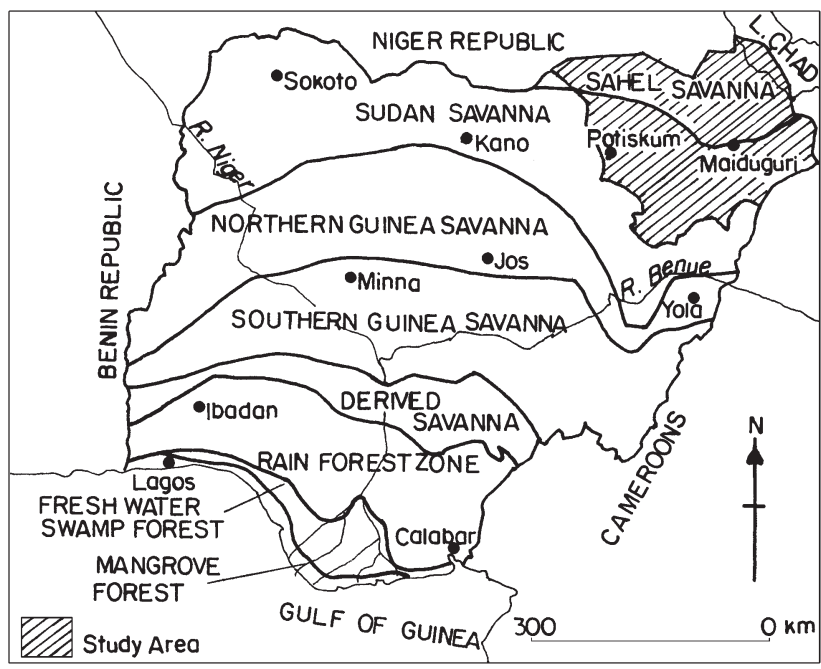

Fig. 1. Ecological zones in Nigeria, and study area
The wet seasons are usually associated with SW monsoon winds, while the dry seasons are associated with dry NE winds from the Sahara Desert. Normally the rainy season begins in June and ends in September or early October (4 to $5 \mathrm{mo}$ ) while the dry season begins in October and ends in May ( 7 to $8 \mathrm{mo}$ ). The heaviest rainfall and the highest number of rainfall days are normally recorded in August. The dry NE winds are typically dust-laden and associated with low night time temperatures. The area is also characterized by extremes of temperature with relatively high diurnal and annual ranges. The coolest months of the year are December, January and February during which mean temperatures fall to between 15 and $25^{\circ} \mathrm{C}$. A sudden rise in temperature occurs during March, April, May and June with mean temperatures of between 34 and $40^{\circ} \mathrm{C}$.

\section{METHODS}

\subsection{Sources of data}

Rainfall data and crop yield data for 1983 to 1999 were used in this study. Daily rainfall data were obtained from the library of the Nigerian Meteorological Agency, Oshodi Lagos State. The data are for two of the standard meteorological stations located in the study area, namely Maiduguri $\left(11.51^{\circ} \mathrm{N} ; 13.07^{\circ} \mathrm{E}\right)$ and Potiskum $\left(11.44^{\circ} \mathrm{N} ; 11.05^{\circ} \mathrm{E}\right)$. The data were recorded at these stations using the British Standard Raingauge and Dine's tilting siphon rainfall recorder (information provided by Agency staff). A brief description of instrumentation is included in the Annual Summary of Observations (e.g. Nigeria Meteorological Services 1953). Data collected using these instruments are subject to instrumental and observer errors, and problems of data homogeneity. For the latter, Adejuwon (1988) showed that the stations employed in this study have not been affected by site relocation, and Odekunle (2004) assessed the data consistency and confirmed the homogeneity. Other reasons to assume that the data are of adequate quality include the fact that the intra-annual distribution of the data reflects rainfall patterns characteristic of the tropical semi-arid climates such as that in Northern Nigeria. The crop yield data for 1988 to 1999 were obtained from the Nigerian Arid Zone Research Institute in Maiduguri, the capital of Bornu. The Institute has responsibility for research and agricultural extension in Bornu and Yobe, among the other dry zone states. The data were generated through an ongoing sample survey of peasant farmer holdings. Data for 12 yr from 1988 to 1999 were available on 6 major crops: cowpeas, ground nuts, millet, maize, 
sorghum and rice. The relevant primary data were on area harvested (ha) and total production ( $\mathrm{kg}$ or $\mathrm{t}$ ). Similar data for the same crops for 1983 to 1993 were collected from the Annual Abstract of Statistics of the Nigerian Federal Office of Statistics (FOS 1986, 1987, 1994). Opinions of peasant farmers were gathered through questionnaires administered to 10 communities in the 2 ecological zones during field surveys.

\subsection{Analysis of data}

Bivariate correlation, multiple correlation and regression analyses were conducted using SPSS (Einstein \& Abernerthy 2000) to assess the relationship between crop yield and climate. The climate variables used in the bivariate correlation analyses included annual and seasonal totals, and monthly rainfall during the growing season. Climate variables used in the multiple correlation and regression analyses consisted of rainfall in June, July, August and September for the stations at Potiskum and Maiduguri. In the regression analysis, the dependent variables were the yields of the various crops, while the independent variables consisted of the monthly rainfall data. Monthly rainfall data were used because optimum crop yield is determined by the adequacy of rainfall at each phase in the growth and development of the crop plants from planting to harvesting, and not by the seasonal total in rainfall. Ideally, each variable ought to represent the weather conditions during identifiable phases of crop growth and development. However because of difficulties in reconstructing the weather for the various phases of crop growth during each of the years covered by the study, I am here adopting monthly rainfall as a proxy.

Each growth phase, which is separately affected by environmental factors, makes its own contribution in determining the total yield. For example, the growth cycle of sorghum may be divided into 3 phases (Kowal \& Andrews 1973, Kassam \& Andrews 1975): (1) vegetative phase, from sowing to panicle initiation; (2) flowering or panicle development phase, from panicle initiation to anthersis and the beginning of grain filling; (3) grain-filling phase (or physiological maturity). Each of these broad phases is composed of sub-phases, which may vary in duration, and may overlap. Each phase also requires different environmental conditions for optimum performance of the crop plant. For example, water consumption by sorghum varies considerably between phases, calling for different amounts of rainfall (Olaniran \& Babatolu 1987). In Kabba, south-central Nigeria, during the period from 1977 to 1984, water available from rainfall during the total growing season of sorghum aver- aged $117 \%$ of the water required. However, while the water supply during the phase of vegetative growth exceeded the requirement by $>120 \%$, the water available during the phase of flowering was only $30 \%$ of the requirement, and the water available during the phase of grain filling was $8 \%$ (Olaniran \& Babatolu 1987).

Since one of our primary objectives was to estimate the relative contributions of each independent climate variable in determining the variability of crop yield, backward selection procedures were used for the regression analyses. The method begins with the regression of yield on all of the 8 monthly explanatory variables. At this stage, $\mathrm{R}$ is at its maximum, as is the number of degrees of freedom and the value of $\alpha$. Invariably, at this first round in the regression analysis $\alpha$ lies outside the limits of significance (0.05) set for the analyses and the model is rejected. The method proceeds by removing the least powerful explanatory variable at each subsequent cycle of regression, creating models with decreasing $R$, decreasing number of variables, decreasing degrees of freedom and improving 'goodness of fit' (Mather 1976). The optimum model is the one with the highest $\mathrm{R}$ while $\alpha \leq 0.05$. The variables entered into SPSS for the regression analysis were the 8 monthly rainfall data of the 2 rainfall stations for the periods from June to September. The optimum model was derived from the 5th cycle of regression (4 predictor variables) for cowpeas, 4th cycle (5 predictors) for groundnut, 4 th cycle (5 predictors) for millet, and 3rd cycle (6 predictors) for sorghum, with 17 observations in each case. Thus the backward selection procedure is not only useful in identifying the more powerful predictors; more importantly it helps to identify models with acceptable levels of stability, i.e. goodness of fit, from the available data. The procedure produced acceptable optimum models for some crops, while for other crops none of the models produced was acceptable, because $\alpha$ remained outside the limits of significance.

\subsection{Indexing variable annual impacts}

The linear approaches failed to address 2 main issues. (1) Magnitude of the annual impact: neither correlation nor regression analysis resulted in the derivation of measures of the impacts of the climate, as they varied from one year to another; $\mathrm{R}^{2}$ gave a measure of the total impact over the entire period of study, not for individual years. (2) Significance of the impact: not every change in crop yield is the result of an impact; there should be a method to discriminate between impacts and mere sensitivity. 
Table 1. Bivariate correlation (R) between monthly rainfall and crop yield in the Nigerian Arid Zone; ${ }^{*} \alpha \leq 0.05 ;{ }^{* *} \alpha \leq 0.01$

\begin{tabular}{|c|c|c|c|c|c|c|c|c|}
\hline & \multicolumn{4}{|c|}{ Potiskum } & \multicolumn{4}{|c|}{ Maiduguri } \\
\hline & JUNP & JULP & AUGP & SEPTP & JUNM & JULM & AUGM & SEPTM \\
\hline Cowpea & 0.45 & $0.50^{*}$ & 0.09 & 0.32 & 0.003 & 0.26 & 0.08 & 0.36 \\
\hline Groundnut & $0.61^{* *}$ & 0.10 & 0.10 & 0.14 & -0.14 & 0.23 & -0.12 & 0.27 \\
\hline Millet & 0.34 & 0.11 & 0.12 & $0.52^{*}$ & 0.06 & 0.30 & 0.22 & 0.23 \\
\hline Maize & 0.12 & -0.06 & 0.21 & 0.01 & 0.05 & -0.03 & 0.11 & 0.15 \\
\hline Sorghum & 0.22 & -0.22 & -0.13 & $0.55^{*}$ & 0.27 & -0.01 & -0.14 & 0.21 \\
\hline Rice & -00.13 & 0.29 & 0.03 & 0.04 & 0.06 & 0.19 & 0.43 & 0.04 \\
\hline
\end{tabular}

If changes in crop yield from one year to the other are caused by the changes in climate, then the impacts represent negative and positive anomalies of crop yield, computed for each year. Thus impact was estimated as: [(annual yield) - (mean annual yield)]/SD. The result was a Z-distribution array with values varying from ca. -3 to +3 . Values $<-1.6$ or $>1.6$ indicate impacts that are significant at the $95 \%$ level, and values $<-2.3$ and $>2.3$ define impacts that are significant at the $99 \%$ level.

\section{RESULTS}

\subsection{Sensitivity to climate variability}

\subsubsection{Determinants of inter-annual changes in crop yield}

At Maiduguri and Potiskum, the bivariate correlations between crop yield and total seasonal rainfall are not significant. The correlations between crop yield and monthly totals at Maiduguri are also not significant (Table 1). However, at Potiskum there are significant positive relationships between cowpea yield and July rainfall (JULP), between groundnut yield and June rainfall (JUNP), between millet yield and September rainfall (SEPTP), and between sorghum yield and September rainfall (SEPTP).

The observation that crop yields in the area of study were in general not strongly affected by rainfall variation in Maiduguri is confirmed by the multiple correlation analysis (backward regression procedure); 15 out of the 24 'most powerful' determinants of crop yield were derived from Potiskum rainfall, and only 9 from Maiduguri rainfall (Table 2). For 5 of the 6 crops, the single most powerful determinant of yield was the rainfall of a given month in Potiskum. Maiduguri is located in the drier Sahelian area, while Postikum is located in the wetter Sudanic area, and it is likely that farm outputs are higher in the Sudanic area. Total farm output should therefore correlate more with Potiskum than with Maiduguri rainfall.
Table 2. The 4 most powerful determinants (monthly rainfall) of crop yield in the Nigerian Arid Zone. The last letter of each variable denotes the station (M: Maiduguri; P: Potiskum), the first 3 or 4 letters denote the month of the year

\begin{tabular}{|lllll|}
\hline & First & Second & Third & Fourth \\
\hline Cowpea & JUNP & SEPTP & JULP & JULM \\
Groundnut & JUNP & SEPTP & JUNM & AUGP \\
Millet & JUNP & SEPTP & JULM & JULP \\
Maize & AUGP & JULM & JULP & SEPTM \\
Sorghum & SEPTP & JULP & AUGM & JULM \\
Rice & AUGM & JUNP & AUGP & JULM \\
\hline
\end{tabular}

\subsubsection{Differential effects of rainfall}

Coefficients of multiple correlation are significant with respect to 4 crops, namely cowpea, groundnut, millet and sorghum (Table 3 ). $\mathrm{R}$ values indicate that sorghum is the most sensitive to climate variability, followed by millet, groundnut and cowpeas. Correlations are not significant in the case of maize $(\mathrm{R}=0.207 ; \alpha=$ 0.425 ) and rice $(\mathrm{R}=0.188 ; \alpha=0.082)$, which are normally cultivated in the more humid zones of the country. A substantial proportion of these crops are produced at 'fadama' sites (poorly drained or swampy valley bottom locations, where soil water is available for plant growth for a period much longer than the rainy season); irrigation is also practiced, based on water stored in shallow hand-dug pits, especially where an impermeable, clayey sub-surface horizon is present. These practices are probably responsible for the lower sensitivity of maize and rice yields.

\subsubsection{Yield predictors}

Only 4 of the optimum predictive models, for cowpeas, groundnuts, millet, and sorghum are characterized by $\alpha \leq 0.05$ (Table 3). The main predictors for cowpeas are JUNP and JULP. The most powerful predictor of groundnut yield is JUNP; the most powerful predictor of millet and sorghum yields is SEPTP. 
Table 3. Influence of rainfall on crop yield in the Nigerian Arid Zone: prediction models having $\alpha \leq 0.05$. See Table 2 for explanation of variables

\begin{tabular}{|c|c|c|c|c|}
\hline Crop & Model & $\mathrm{R}$ & $\mathrm{R}^{2}$ & $\alpha$ \\
\hline Cowpea & Yield $=1.701 \mathrm{JUNP}+1.003 \mathrm{JULP}+0.721 \mathrm{SEPTP}+0.402 \mathrm{JULM}-10.759$ & 0.737 & 0.543 & 0.039 \\
\hline Groundnut & Yield $=4.123 \mathrm{JUNP}+1.533 \mathrm{JULM}-1.270 \mathrm{JUNM}+1.266 \mathrm{SEPTP}-0.759 \mathrm{AUGP}+348$ & 0.771 & 0.595 & 0.049 \\
\hline Millet & Yield $=1.870$ SEPTP $+1.406 \mathrm{JUNP}+1.332 \mathrm{JULM}-0.404 \mathrm{JULP}-0.381 \mathrm{SEPTM}+490$ & 0.773 & 0.598 & 0.047 \\
\hline Sorghum & Yield $=3.148 \mathrm{SEPTP}-1.842 \mathrm{JULP}-1.604 \mathrm{AUGM}+1.560 \mathrm{JUNP}+1.345 \mathrm{JULM}+0.594 \mathrm{JUNM}+963$ & 0.815 & 0.663 & 0.047 \\
\hline
\end{tabular}

$\mathrm{R}^{2}$ values show that two-thirds of the variability in the yield of sorghum is determined by rainfall variability. For groundnut and millet, the proportion of the variability in yield determined by rainfall variability is $60 \%$, while for cowpeas the proportion is $54 \%$. Based on the backward selection procedure, JUNP is a more powerful predictor of crop yield than any of the other monthly rainfall variables. It is the most powerful predictor for cowpea, groundnut and millet. This is explained by the fact that June is the month of the onset of the rainy season; low June rainfall implies a delayed onset of the rainy season, which becomes too short for most crops. In the case of sorghum, SEPTP is the most powerful predictor; September is the month of cessation of the rainy season. Low or inadequate rain in September is evidence that the season is truncated before it could provide adequate moisture for crops during the critical phases of grain filling. This can be most damaging to crops with a growing period $>4 \mathrm{mo}$, i.e. longer than the rainy season.

\subsection{Variable annual impacts of climate}

Of the anomalies of crop yield for the 6 crops over the study period of $17 \mathrm{yr}$ (102 records), 34 are negative, while 68 are positive (Fig. 2). Only 7 anomalies are significant $(Z \geq 1.66) ; 6$ anomalies are significant at the $95 \%$ confidence limit and 1 is significant at the 99\% level. Therefore, 95 of the 102 cases can be described as normal yield levels. This corresponds to the recollection of the farmers to the effect that in most years, climate does not impact on their livelihood, apart from the usual anxiety over the time of arrival of the first rains. There were 5 years between 1983 and 1999 with significant departures from the yield in 1 or more crops. Overall, the signals from the various years and crops are mixed. The worst weather for crop growth was in 1990, while the best was in 1994, when the rains started early in June and did not stop until the last third of September. Most of the other years were similar with respect to rainfall distribution. The significant positive anomaly for millet yield could have resulted from a combination of favourable conditions other than rainfall. In 1990, the low crop yields were due to drought.

\subsection{Impact of the 1990 drought}

In 1990, all crops recorded their highest negative yield anomalies for the study period, except for cowpeas, which recorded the second highest. In 1990, total growing season rainfall for Potiskum was the lowest during the $17 \mathrm{yr}$ period (319 $\mathrm{mm}$, i.e. $53 \%$ of the longterm mean) (Table 4). For Maiduguri, the total seasonal rainfall of $407 \mathrm{~mm}$ was the 6 th lowest.

The rainfall patterns for June to September for the 2 stations are depicted in Table 5. Given the fact that daily rainfall of at least 3 to $5 \mathrm{~mm}$ is required to balance evaporation and transpiration (Garnier 1961), the $25 \mathrm{~mm}$ of rainfall at Potiskum in June 1990, when the rainy season was delayed, was grossly inadequate to wet the fields before tilling and planting; in addition, rain stopped abruptly in the first 2 wk of September, when cereal crops planted in the middle of July would be at the period of grain filling. Thus the growing season in that year lasted only 2 mo (the 2 showers in mid and late September were ineffective). In Maiduguri, the first effective rain was recorded on June 27 , i.e. the rainy season effectively started in July, and the total for September was only $40 \mathrm{~mm}$. Thus, in Maiduguri the effective rainy season was also too short for the needs of the major crops, especially sorghum and maize. With this pattern of rainfall, 1990 is an example of a drought year. The widespread drought of 1973-1974 was remembered by the population in our study area, according to the field survey. However, the droughts observed in 1983 and 1987 in other parts of the Nigerian Arid Zone did not have any significant impact on crop yields, according to the data available. The people could recall bad harvests in 1973, which resulted from early cessation of the rains; animals also suffered when the grass dried up for prolonged periods. Apart from 1973 and 1990, farmers recollected only good harvests during the past 30 yr. According to them, the drought of 1990 was not as severe as that of 1973-1974. But major widespread droughts are rare, whereas local droughts are common (Adejuwon et al. 1990). 

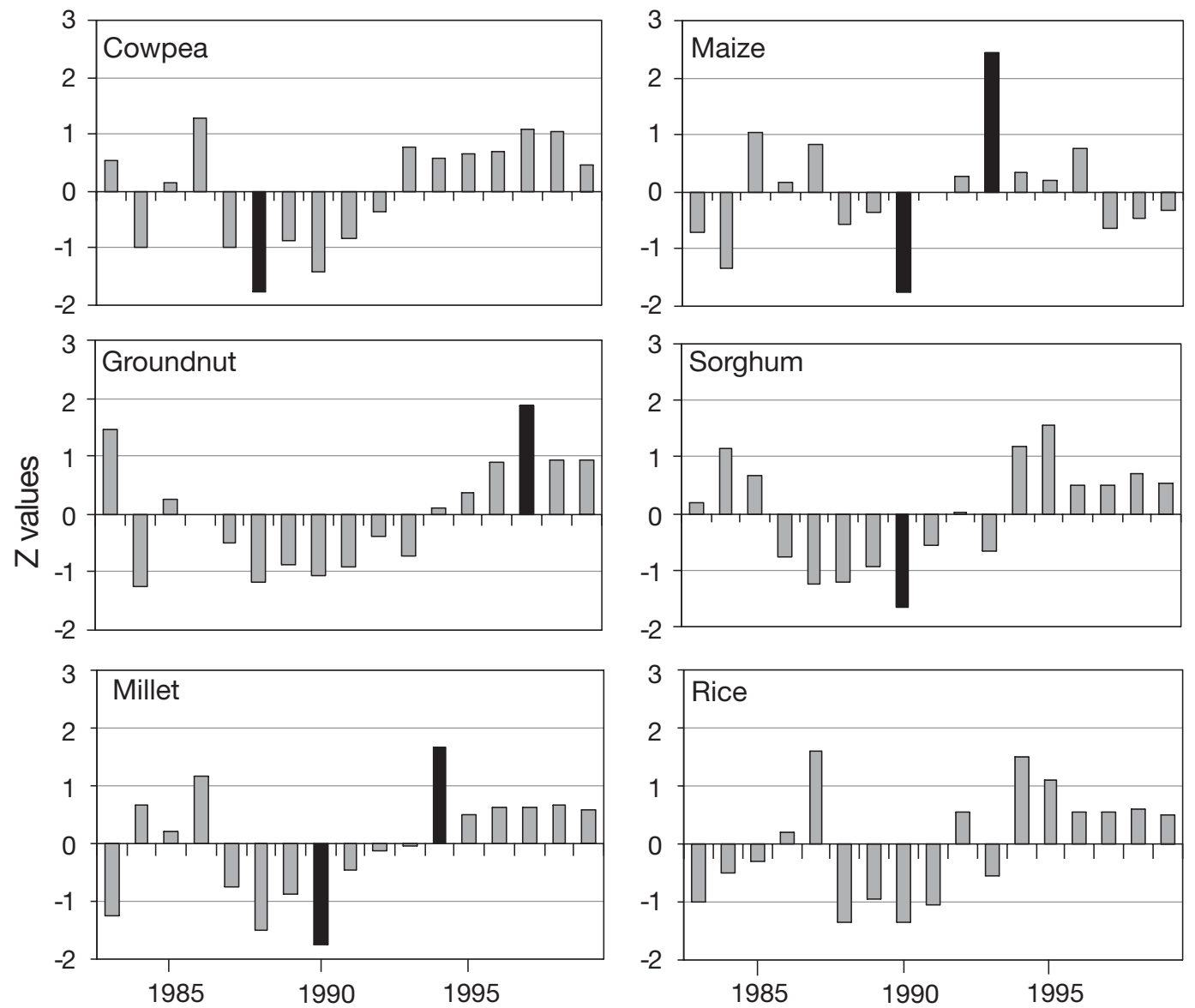

Fig. 2. Crop yield anomalies in the Nigerian Arid Zone from 1983 to 1999. Black columns represent significant anomalies

Table 4. Growing season rainfall $(\mathrm{mm})$ in Potiskum and Maiduguri, Nigeria, for 1983-1999. Total: June to September. COV: coefficient of variation

\begin{tabular}{|c|c|c|c|c|c|c|c|c|c|c|}
\hline Year & Total & Jun & $\begin{array}{l}\text { Potiskum } \\
\text { Jul }\end{array}$ & Aug & Sep & Total & Jun & $\begin{array}{l}\text { Maiduguri } \\
\text { Jul }\end{array}$ & Aug & Sep \\
\hline 1983 & 522.5 & 53.8 & 224 & 161 & 83.7 & 254.4 & 37.1 & 80.8 & 92.7 & 43.8 \\
\hline 1984 & 398.2 & 16.9 & 106 & 141.9 & 133.4 & 312.6 & 39.5 & 142.2 & 105 & 25.9 \\
\hline 1985 & 533.2 & 86.6 & 160 & 203.6 & 83 & 377 & 83.1 & 56.9 & 96 & 141 \\
\hline 1986 & 772.2 & 88.7 & 361 & 181.9 & 140.6 & 509.1 & 23 & 166.8 & 145.2 & 174.1 \\
\hline 1987 & 348.1 & 70.6 & 122.9 & 154.6 & 0 & 332.4 & 32.2 & 106.7 & 174.2 & 19.3 \\
\hline 1988 & 964.3 & 77.4 & 248.1 & 535 & 103.8 & 605.8 & 85.3 & 181.9 & 256.5 & 82.1 \\
\hline 1989 & 668.2 & 113.9 & 254.2 & 170.5 & 129.6 & 531.8 & 90.2 & 117 & 220.1 & 104.5 \\
\hline 1990 & 319.4 & 25 & 189.5 & 85.6 & 19.3 & 407.1 & 46 & 183.7 & 137.7 & 39.7 \\
\hline 1991 & 489.8 & 97.7 & 124.2 & 267.9 & 0 & 396.3 & 100.3 & 90.3 & 205.4 & 0.3 \\
\hline 1992 & 572.3 & 22.8 & 166.6 & 197.3 & 185.6 & 512.1 & 40.5 & 113.3 & 296.4 & 61.9 \\
\hline 1993 & 591.8 & 44.8 & 203.2 & 281.7 & 62.1 & 423.1 & 19.8 & 204 & 149.8 & 49.5 \\
\hline 1994 & 727.5 & 78.5 & 183.1 & 267.6 & 198.3 & 285.1 & 50.4 & 66.3 & 168.4 & 0 \\
\hline 1995 & 552 & 90.2 & 182.1 & 115 & 164.7 & 767.6 & 222 & 175.3 & 175.3 & 195 \\
\hline 1996 & 648.6 & 149.2 & 135.2 & 241.7 & 122.5 & 568 & 58.2 & 195.8 & 176.6 & 137.4 \\
\hline 1997 & 611.6 & 194.8 & 194.1 & 147.1 & 75.6 & 464 & 136 & 137.7 & 130 & 60.3 \\
\hline 1998 & 719.9 & 155.8 & 171.1 & 317 & 76 & 507.4 & 59.8 & 179 & 268.6 & 0 \\
\hline 1999 & 712.1 & 36.4 & 306.7 & 284.9 & 84.1 & 786.9 & 25.9 & 342.7 & 186.5 & 231.8 \\
\hline Mean & 597.2 & 82.5 & 196.0 & 220.8 & 97.8 & 473 & 59.61 & 149.44 & 175.5 & 80.39 \\
\hline SD & 162.3 & 49.7 & 67.0 & 104.5 & 58.7 & 152.1 & 50.06 & 68.29 & 59.2 & 72.06 \\
\hline $\mathrm{COV}$ & 27.1 & 60.2 & 34.2 & 47.3 & 60.0 & 32.2 & 83.98 & 45.70 & 33.7 & 89.64 \\
\hline
\end{tabular}


Table 5. Daily rainfall (mm) in 1990 at Potiskum and Maiduguri, Nigeria. $\operatorname{Tr}=$ trace

\begin{tabular}{|c|c|c|c|c|c|c|c|c|}
\hline \multirow[t]{2}{*}{ Day } & \multicolumn{4}{|c|}{ Potiskum } & \multicolumn{4}{|c|}{ Maiduguri } \\
\hline & Jun & Jul & Aug & Sep & Jun & Jul & Aug & Sep \\
\hline 1 & 0 & 17.3 & 0 & 0 & 0 & 0 & 0 & 0 \\
\hline 2 & 0 & 8.9 & 0 & 0 & 0 & 2.7 & 18.6 & $\operatorname{Tr}$ \\
\hline 3 & 0 & 0 & 0 & 0 & 0 & 0 & 0 & 0 \\
\hline 4 & 0 & 0 & 7.0 & $\operatorname{Tr}$ & 0 & 0 & 45.6 & 14.5 \\
\hline 5 & 0 & 0 & 0 & 0 & 0 & 0 & 0 & 0 \\
\hline 6 & 0 & 0 & 0 & 0 & 0 & 4.5 & 0 & 0 \\
\hline 7 & 0 & 40.9 & 0 & 0 & 0 & 0 & 6.6 & 0 \\
\hline 8 & 0 & 0 & 8.0 & 0 & 0 & 0 & $\operatorname{Tr}$ & 0 \\
\hline 9 & 0 & 0 & 0 & $\operatorname{Tr}$ & 0 & 0 & 0 & 0.3 \\
\hline 10 & 0 & 0 & 0 & 0 & 0 & 0 & 0 & 0 \\
\hline 11 & 0 & 0 & 0 & $\operatorname{Tr}$ & 0 & 0 & 0 & 0 \\
\hline 12 & 0 & 22.8 & 0 & 0 & 10.6 & 0 & $\mathrm{Tr}$ & \\
\hline 13 & 0 & 0 & 7.0 & 0 & 0 & 24.8 & 0.1 & 0 \\
\hline 14 & 0 & 8.6 & 0 & 12.5 & 2.6 & 0.1 & $\operatorname{Tr}$ & 0 \\
\hline 15 & 0 & 0 & 0 & 0 & 0 & 0 & 2.2 & 0.1 \\
\hline 16 & 0 & 0 & 0 & 0 & 0 & $\operatorname{Tr}$ & 0 & 0 \\
\hline 17 & 0 & 26.9 & 26.6 & 0 & 0 & 21.2 & 5.4 & 0 \\
\hline 18 & 2.6 & 0 & & 0 & 3.2 & 20.4 & 0 & 11.6 \\
\hline 19 & 0 & 29.0 & 5.2 & 0 & 0 & 2.0 & 5.0 & 0 \\
\hline 20 & 0 & 0 & 0 & 0 & 0 & 0 & 0 & 0 \\
\hline 21 & 0 & 0 & 0 & 0 & 0 & $\operatorname{Tr}$ & 0 & 0 \\
\hline 22 & 0 & 3.3 & 0 & 0 & 0 & 33.6 & 0 & 0 \\
\hline 23 & 0 & 0 & 0 & 6.8 & 4.4 & $\operatorname{Tr}$ & 0 & 13.2 \\
\hline 24 & $\operatorname{Tr}$ & 0 & 0 & 0 & 0 & 1.5 & 0 & 0 \\
\hline 25 & 1.3 & 0 & 14.9 & 0 & $\operatorname{Tr}$ & 0 & 54.2 & 0 \\
\hline 26 & 0 & 21.8 & 0 & 0 & 0 & 54.8 & 0 & 0 \\
\hline 27 & 11.5 & 0 & 0 & 0 & 13.0 & $\operatorname{Tr}$ & 0 & 0 \\
\hline 28 & 0 & 0 & 0 & 0 & 22.8 & 0 & 0 & 0 \\
\hline 29 & 9.6 & 7.5 & 0 & 0 & 0 & $\operatorname{Tr}$ & $\mathrm{Tr}$ & 0 \\
\hline 30 & 0 & 2.8 & 0 & 0 & 0 & 1.5 & 0 & $\operatorname{Tr}$ \\
\hline 31 & - & 0 & 16.9 & - & - & 6.0 & 0 & - \\
\hline Total & 25.0 & 189.8 & 85.6 & 19.3 & 46.0 & 183.7 & 137.7 & 39.7 \\
\hline
\end{tabular}

\section{DISCUSSION}

Some of the main findings in this study are related to its methodology. We adopted a definition of impact as a measure of crop yield sensitivity to inter-annual changes in climate (rainfall), determined by linear bivariate correlations. Total seasonal rainfall was not significantly correlated with crop yield. Better results were achieved by adopting monthly rainfall in the growing season as the independent variable, which better reflects the multiplicity of impacts on crop growth, development, flowering, seed production and maturity. The totality of the impacts was achieved cumulatively from a dynamic climate pattern, i.e. the methodology had to reflect a multiplicity of rainfall variables. Multivariate correlation and regression analyses provided us with a methodology for adding up the impact components into a single seasonal climate impact.

The crop whose yield was most sensitive to rainfall variability was sorghum, followed by millet, groundnut and cowpeas. Maize and rice yields were the least sensitive to rainfall variability, probably due to the fact that these crops are more likely to be irrigated. Negative impacts of climate are more likely to result from inadequate rainfall in June, in September or in both months. Sorghum is particularly susceptible to the vagaries of September rainfall because of its very long growing period.

One basic requirement of linear models is that both the independent and the dependent variables must be continuous and continuously associated (Dunteman 1984). However, even where both the dependent and the independent data are separately continuous, the relationship might not be continuous. For example the relationship between variability of crop yield and variability of the weather is not always continuous. Climatic risks to crop production are produced more by extreme events, such as the drought of 1990, than by inter-annual rainfall variability; $94 \%$ of the variability in rainfall did not produce significant impacts, neither positive nor negative ones.

The sensitivity of crop yield to moisture and rainfall appears to be subject to the 'ecological law of the minimum' propounded by Liebig (1847), according to which changes in yield will result when rainfall and moisture supply approach the critical minimum (Odum 1971). Whenever moisture supply is adequate, change in crop yield will cease to depend on this variable, i.e. it will no longer be the limiting factor. For example, if rainfall were adequate for optimum crop yield over a period of $30 \mathrm{yr}$, moisture variability would have no impact on crop yield; therefore, the impact of rainfall on crop yield is discontinuous, and this weakens the linear relationship, reduces the magnitude of the coefficients of correlation and makes it difficult to develop measures of impact based on linear models.

In 1990, rainfall seems to have fallen to values approaching the critical minimum of 4 of the 6 crops, leading to significant negative anomalies in yield. Differences between crops may occur because the critical minimum of rainfall, the length of the period from planting to harvesting, and the time of planting vary.

\section{CONCLUSIONS}

Monthly rainfall is a more powerful determinant of inter-annual changes in crop yield than total annual and total seasonal rainfall. Rainfall at the onset and the cessation of the rainy season contributes more to interannual crop yield variability than rainfall in the other months. These findings are useful, given that extended-range weather forecasters still concentrate on the prediction of total seasonal rainfall instead of monthly and sub-seasonal components. Correlation 
between crop yield and rainfall variability is strongest when rainfall values approach the critical minimum (Liebig's 'law of the minimum').

Interviews with farmers confirm that years of drought with abnormally low crop yields are rare. During such years crop failures are recorded for most crops. Research and management do not adequately reflect the fact that real drought occurs seldom. For example, the building of grain reserves requires different strategies depending on whether it is for disaster relief or for reducing seasonal deficits. Prediction of droughts should be a separate research topic from prediction of seasonal weather, not only because of the differences in risk, but also because they result from different weather mechanisms (Adedokun 1978).

Acknowledgements This study is part of a research project funded and supported by START (SysTem for Analysis, Research and Training), NOAA (National Oceanic and Atmospheric Organization of the USA) and AIACC (Assessment of Impacts and Adaptations to Climate Change); AIACC is supported by START, TWAS (Third World Academy of Sciences) and UNEP (United Nations Environment Programme).

\section{LITERATURE CITED}

Adedokun JA (1978) West African precipitation and dominant atmospheric mechanisms. Arch Meteorol Geophys Bioklimatol Ser A 27:289-310

Adejuwon JO, Balogun EE, Adejuwon SA (1990) On the annual and seasonal patterns of rainfall fluctuations in sub-Saharan West Africa. Int J Climatol 10:839-848

Adejuwon JO, Odekunle TO (2004) Skill assessment of the

Editorial responsibility: Otto Kinne,

Oldendorf/Luhe, Germany existing capacity for extended range weather forecasting in Nigeria. Int J Climatol 23:1249-1265

Adejuwon SA (1988) An assessment of rainfall fluctuations between 1922 and 1985 in Nigeria. PhD thesis, Obafemi Awolowo University, Ile-Ife, Nigeria

Daubenmire RF (1974) Plants and environment. Wiley, New York

Dunteman GH (1984) Introduction to linear models. Sage Publications, London

Einstein G, Abernerthy K (2000) Statistical package for the social sciences, SPSS Version 10.1. Furman University, Greenville, SC

FOS (1986) National Agricultural Sample Survey: 1984/85, 1985/86. Federal Office of Statistics, Lagos, Nigeria

FOS (1987) National Agricultural Sample Survey, 1986/87. Federal Office of Statistics, Lagos, Nigeria

FOS (1994) National Agricultural Sample Survey, 1992/93. Federal Office of Statistics, Lagos, Nigeria

Garnier BJ (1961) Delimitation of the humid tropics. Geogr Rev 57:339-347

Kassam AH, Andrews DJ (1975) Effects of sowing dates on growth, development and yield of photosynthetic sorghum at Samaru, Northern Nigeria. Exp Agric 11:227-240

Kowal J, Andrews DJ (1973) Pattern of water availability and water requirement for grain sorghum produced at Samaru, Nigeria. Trop Agric (Trinidad) 50:89-100

Liebig J (1840) Chemistry in its application to agriculture and physiology. Taylor \& Walton, London

Mather PM (1976) Computational methods of multivariate analysis in physical geography, Wiley, London

Nigeria Meteorological Services (1953) Annual summary of observations. Federal Government Printer, Lagos

Odekunle TO (2004) Rainfall and the length of the growing season in Nigeria. Int J Climatol 24:467-479

Odum EP (1971) Fundamentals of ecology. Saunders, Philadelphia, PA

Olaniran OJ, Babatolu JS (1987) Climate and the growth of sorghum at Kabba, Nigeria. J Agric Meteorol 42:301-308

Riehl R (1954) Tropical meteorology. McGraw Hill, New York

Submitted: October 27, 2004; Accepted: October 6, 2005

Proofs received from author(s): November 2, 2005 